\title{
The Degree of Availability of Skills Needed to Build and Employ Electronic Exams for Faculty Members at the University of Jeddah
}

\author{
Ali bin Muhammad Al-Kalthmi Al-Shehri ${ }^{1}$, Majed Abdallah Al Harthi ${ }^{2}$
}

\begin{tabular}{l} 
ARTICLE INFO \\
\hline Article History: \\
Received 04.07.2020 \\
Received in revised form \\
24.04 .2021 \\
Accepted \\
Available online 01.07 .2021
\end{tabular}

\begin{abstract}
This study aims at identifying the degree of availability of skills needed to build and employ electronic exams for faculty members at the University of Jeddah in light of the global trend in elearning. The study used the descriptive and analytical approach and used a scale applied to a sample of (297) faculty members from the University of Jeddah in the Kingdom of Saudi Arabia. The results of the study concluded that the skills needed to build electronic exams for faculty members had a high degree, with a mean score of (3.45) and a standard deviation of (0.444). The results revealed that the necessary skills to employ electronic exams had a high degree of response, with a mean score of (3.45) and a standard deviation of (0.789). The study recommends conducting training courses for faculty members at the University of Jeddah on building electronic exams and attracting experts to train faculty members on the methods of employing electronic exams.
\end{abstract}

C IJERE. All rights reserved

Keywords:

Electronic exams, e-learning, global trend, University of Jeddah.

\section{INTRODUCTION}

The need for the development of learning methods and the use of technology has emerged as a necessity because of the rapid developments occurring in the different fields in the world today, which led to the emergence of the so-called e-learning. Damour (2020) pointed out that e-learning "is students' learning through electronic means such as the Internet, local networks, data projectors, PowerPoint, and CDs "(p. 43). Among the most prominent innovations of e-learning are electronic exams, which are "one of the subprocesses in the overall teaching and learning process, in which the learner's performance is determined by evaluating the knowledge or skills that the learners have gained after a period of a specific program of online education" (Ataman, 2020; Karagoz,2021; Kucuker,2019; Moawad 2020). The technology of building and producing electronic exams has allowed test designers several alternative designs, including true and false, multiple-choice, pairing, essay questions, and the inclusion of text, pictures, or video, with answers to questions whether they are visible according to a specific system or randomly. In this way, the same exam is presented in more than one form with the possibility of random ordering of questions (Suleiman \& Suleiman, 2020).

The University of Jeddah uses the blackboard system, which is an MIS that provides electronic selfservices in a specific unified system on the internet, allowing users to use the services in a friendly user environment. The system allows faculty members to build exams and employ them for the materials for their courses. The university report, "The E-Learning Center Report on the Progress of the E-Learning Process at the University of Jeddah," indicates the availability of more than 225 hours of support for the face-to-face and remote exams for more than 71,400 exams (Jeddah University, 2020). This requires effort, knowledge, and skills on the part of the faculty members. Because of the global trend to use e-learning, especially in light of the current global conditions represented by the emergence of the Corona pandemic, most universities sought to enhance the capabilities of faculty members and workers to cope with these developments. In the field of electronic exams, the faculty member should possess the skill of diagnosing and evaluating the student's level of knowledge, mental, and practical aspects. This is necessary for employing electronic exams. Abu Bakr and Adebayo (2014) emphasized that electronic exams are used to assess abilities and levels of cognitive and knowledge performance using electronic test software, as well as performance and practical levels using simulation software.

Several previous studies have indicated the importance of possessing several skills related to electronic exams. Khadka, Rokaya, Roka, \& Bhatta, 2020) indicated a lack of training and skills needed to use technology among university instructors and students alike. The faculty member's competencies in the electronic environment include several important skills. The educational skills include experience in the subject matter,

1 arabia.alshehri1@uj.edu.sa, orcid.org/0000-0002-1484-2175, University of Jeddah, College of Education

2 malharthy@uj.edu.sa, orcid.org/0000-0003-3176-1796, University of Jeddah, College of Education 
training, and evaluation. social skills include interpersonal skills, communication, and facilitation skills. Administrative skills include leadership and management skills. Technical skills include technical knowledge and professional skills that are related to planning, analysis, design, development, application, management, communication, interaction, teaching, learning, management, and use of technology. The competencies should include also knowledge of pedagogical methods, such as motivation, presentation, questioning, clarification, correction, retention, environmental management, and appropriate use of technology (Gulbahar \& Kalelioglu, 2015).

\section{The Problem of the Study}

Despite the trend towards using electronic exams, several challenges are present in the lack of orientation and skills of faculty members in building and employing electronic exams. Since Jeddah University uses one of the electronic systems for e-learning and electronic examination, there is an urgent need to measure the extent of faculty members' knowledge of this system and the availability of the skills necessary to build and employ electronic exams. In addition, many challenges face faculty members in developing skills for building electronic exams, including the lack of a computer lab, which led to the reluctance in applying electronic exams. Faculty members lack knowledge in computer skills, which is a reason for not applying the electronic test system and electronic exams and add to the difficulty of developing essay questions and designing electronic exams. This phenomenon exists in other universities as well. Mouawad (2020) indicated the deficiency of electronic test design skills and the low skill level of electronic test design skills among faculty members at Prince Sattam bin Abdulaziz University. Therefore, this study attempted to address measuring the level of skills needed to build and employ electronic exams among faculty members at the University of Jeddah.

\section{Questions of the study}

The study attempted to answer the following two main questions:

1. What are the skills needed to build electronic exams for faculty members at the University of Jeddah in light of the global trend towards e-learning?

2. What are the skills needed to employ electronic exams for faculty members at the University of Jeddah in light of the global trend towards e-learning?

\section{Objectives of the study}

The research objectives are the following:

1. Identifying the skills needed to build electronic exams for faculty members at the University of Jeddah in light of the global trend for employing e-learning.

2. Identifying the skills needed to employ electronic exams for faculty members at the University of Jeddah in light of the global trend for employing e-learning.

\section{Significance of the study}

The significance of this study is divided into theoretical and practical significance. The theoretical significance is based on addressing electronic examination as an important tool in education in light of the trend towards e-learning. This study could be a starting point for other researchers to reveal more skills needed to build and employ electronic tests. The practical significance comes from the nature of the study as field research that deals with the skills necessary to build and employ electronic exams for faculty members at the University of Jeddah in light of the global trend to employ e-learning. It is hoped that the results and recommendations of the current research will be used in conducting training courses to develop the skills of building and employing electronic exams for faculty members in Saudi universities.

\section{Delimitations of the study}

Thematic limitations: the study is limited to addressing the skills needed to build and employ electronic exams for faculty members at the University of Jeddah in light of the global trend to employ e-learning. 
Spatial limitations: The current study was applied at the University of Jeddah, Saudi Arabia.

Human limitations: The study was limited to the faculty members at the University of Jeddah, Saudi Arabia.

Time limitations: The current study was applied in the first semester of the academic year 2020/2021.

\section{The importance of electronic exams}

Electronic exams represent one of the electronic assessment tools that can be used to overcome the difficulties that hinder the implementation of traditional paper-based tests. They can also be used to provide other channels for measuring students' educational achievement, consolidating information, and developing self-learning skills (Muhammad, 2017). Electronic tests play a prominent role in enabling educational institutions to employ electronic technologies in developing their educational performance by making use of their tools. Therefore, electronic exams occupy an important part in the teaching and learning process and occupy a large amount of time devoted to the learning process (Hassan, 2015). Electronic exams are built and presented through the computer with a high degree of accuracy. They save a lot of effort and time and give more stable and objective results to use them in determining the appropriate activities and educational levels, as teachers rely on software that helps in building these tests (Swordsman \& Honorary, 2013). The technology of building and producing electronic exams has allowed test designers different alternative types of questions, including true and false, multiple-choice, pairing, essay questions, and the inclusion of text, pictures, or video, with answers to questions whether they are visible according to a specific system or random. The exams in this way can be used in more than one form with the possibility of random ordering of questions (Suleiman \& Suleiman, 2020). When building electronic exams, a set of skills must be taken into account when designing the types of questions within the exams. The first of these skills is designing and building electronic exams and the ability to control the test time. These skills include several elements, such as the number and type of questions, the time of presentation of the multimedia, the characteristics of the learners, and the skill of securing the test program. They also include confirming the identity of the user, as well as the immediate correction of the learners' answers and their announcement. The method of correction varies according to the type of test questions. Feedback skills are also required, as the evaluation through the computer contributes to provide immediate feedback and grants the learner the required number of attempts and obtain feedback with each attempt, whether the feedback is directive or non-directive (Seif, 2016). Another important skill is managing the electronic exam: This is done by reviewing the electronic exam before sending it to students, sharing the test with others, saving the test results in different formats, and uploading the results file for the electronic test to a computer or Google Drive" (Suleiman \& Suleiman, 2020).

\section{Skills of employing electronic exams}

Skills for employing electronic exams include different sub-skills. First, skills of identifying types of questions. The process of employing electronic exams requires having the ability to select the appropriate type of questions that are compatible with the nature of the electronic tests. Rytkonen (2015,) emphasized that electronic exams are used to accommodate all types of questions, such as multiple-choice questions, essay questions, and questions that help assess the level.

Second, multimedia use skills. Employing electronic exams requires possession of a background in multimedia, and using them to suit the nature of the test and the target age group. Amira, Ewais, and Hadrob (2018) confirmed that electronic exams are used in applications to measure levels of e-learning when they are used within educational platforms depending on the various multimedia provided, such as animation, 3D models, simulation models, and video and audio files.

Third, sustainability skills. The process of employing electronic exams requires the ability to save time, cost, and materials used in preparing the tests. Bahbouh, Bin Siddiq, Abi Sen, Al-Hafez, and Al-Khudari (2019) stated that "electronic exams are used within higher education contexts in universities largely due to the timesaving features they provide, cost, effort, overcoming bias, human errors and providing a great deal of fairness in evaluation." 


\section{METHODOLOGY}

The study used the descriptive method, which is defined as a "systematic method for studying current facts related to a phenomenon, situation, individuals, or specific events or situations, to discover new facts or verify the validity of old facts, their effects, relationships, change, and revealing the aspects that govern them" (Sultania and Gilani, 2012, p. 133).

\section{Sampling}

The study population consisted of all (1521) faculty members at the University of Jeddah (the official website of the General Authority for Statistics, 2020). To identify the number of the research sample, Richard Geiger's equation was used as follows:

$$
n=\frac{\left(\frac{z}{d}\right)^{2} \times(0.50)^{2}}{1+\frac{1}{N}\left[\left(\frac{z}{d}\right)^{2} \times(0.50)^{2}-1\right]}
$$

\section{$\mathrm{N}$ : $\quad$ population of the study}

Z: $\quad$ The standard score corresponding to the significance (.95), which is equal to (1.96).

\section{D: $\quad$ Error rate}

By applying Richard Geiger's equation to the research population, the study sample consisted of (307) members of the faculty at the University of Jeddah, and the final sample consisted of (297) members, with a rate of $(96.74 \%)$, after excluding (10) members for their incompleteness.

\section{Instrumentation}

The study developed a scale to uncover the necessary skills to build and employ electronic exams for faculty members at the University of Jeddah in light of the global trend to employ e-learning.

The scale contained in its final form two main parts:

- The first part: the skills needed to build electronic exams, and it consisted of paragraphs 1-30.

- The second part: the skills needed to employ electronic exams, and it consisted of paragraphs 31-40.

The five-point Likert scale has been used to correct the search instrument. The answers were given corresponding rates as follows: strongly disagree (1), disagree (2), somehow agree (3) agree (4), strongly agree (5).

\section{Validity and reliability of the instrument}

The scale was sent to several specialized professors, to judge the suitability, clarity, and relevance of the paragraphs of the scale. $80 \%$ of the judges agreed on the suitability of the linguistic formulation of the paragraphs. The scale was applied to an exploratory sample of (30) faculty members at the University of Jeddah. The scale became in its final form after verifying its apparent validity, consisting of (40) paragraphs distributed on two dimensions.

The validity of the internal consistency was calculated using the Pearson correlation coefficient between the degrees of each paragraph and the total score of the scale. The correlation coefficients of the paragraphs with the total degree of the first dimension were $\left(0.770-0.989^{* *}\right)$, and in the second dimension $\left(0.803-0.977^{* *}\right)$. All of these rates were statistically significant at (0.01).

The constructive validity of the scale's dimensions was verified by calculating the Pearson correlation coefficients between the total score of each dimension and the total score of the scale, which was (0.943-0.993 $\left.{ }^{* *}\right)$, and all of them were statistically significant at $(0.01)$. This indicates the availability of a high degree of constructive validity of the scale.

The coefficient of stability of the Cronbach alpha was calculated for the scales' dimensions. The values of the Cronbach's alpha coefficients for the scale were (0.970 -0.996), and the value of the overall reliability coefficient of the scale was (0.980). These values of the reliability factor indicate the validity of the scale for applicability and the reliability and validity of its results.

Data analysis 
Based on the nature of the research and its objectives, the data were analyzed using the Statistical Package for Social Sciences (SPSS) program and the results were extracted according to the following statistical methods: frequencies, percentages, mean scores, standard deviations, Pearson correlation coefficient, and Cronbach's alpha coefficient.

\section{RESULTS}

Results of the first question

To answer the first question, the mean scores and standard deviations of the dimensions of the first part were calculated. The first part included (5) dimensions, which were arranged in descending order according to the mean score of each dimension as shown in the following Table:

Table 1. The mean scores and standard deviations of the responses of the sample about the skills needed to build electronic exams

\begin{tabular}{|c|c|c|c|c|c|}
\hline No. & Dimension & $\begin{array}{l}\text { Mean } \\
\text { score }\end{array}$ & ${ }_{\text {Dev }}{ }^{\text {St. }}$ & Order & $\begin{array}{l}\text { Response } \\
\text { rate }\end{array}$ \\
\hline 1 & The first dimension: electronic questions & 3.45 & 0.657 & 3 & High \\
\hline 2 & The second dimension: Multimedia & 3.48 & 0.838 & 2 & High \\
\hline 3 & The third dimension: test time skills & 3.53 & 0.921 & 1 & High \\
\hline 4 & The fourth dimension: test evaluation skills & 3.40 & 1.143 & 5 & High \\
\hline 5 & The fifth dimension: test security skills & 3.41 & 0.961 & 4 & High \\
\hline \multicolumn{2}{|c|}{ Total score } & 3.45 & 0.444 & & High \\
\hline
\end{tabular}

Table (1) shows that the general mean score for the first part of the scale, the skills needed to build electronic exams had a high response score, with a mean score of (3.45) and a standard deviation of (0.444).

The skills needed to build electronic exams have several dimensions addressed in this study as follows:

The first dimension: electronic questions

The mean scores and standard deviations of the paragraphs of the first dimension were calculated, and then these paragraphs were arranged in descending order according to the mean score of each paragraph, as shown in the following table:

Table (2): The mean scores and standard deviations of the sample' responses to the electronic questions

\begin{tabular}{|c|c|c|c|c|c|}
\hline NO. & Paragraph & $\begin{array}{l}\text { Mean } \\
\text { score }\end{array}$ & St. Dev & Order & $\begin{array}{l}\text { Response } \\
\text { rate }\end{array}$ \\
\hline 1 & $\begin{array}{l}\text { The faculty member's ability to formulate essay } \\
\text { questions. }\end{array}$ & 3.55 & 1.153 & 2 & High \\
\hline 2 & $\begin{array}{l}\text { Faculty member's ability to formulate multiple-choice } \\
\text { questions. }\end{array}$ & 3.31 & 1.340 & 9 & Medium \\
\hline 3 & $\begin{array}{l}\text { The faculty member's ability to formulate true and false } \\
\text { questions }\end{array}$ & 3.45 & 1.268 & 5 & High \\
\hline 4 & $\begin{array}{l}\text { The ability of the faculty member to formulate ordering } \\
\text { questions (phrases, words, concepts, historical } \\
\text { events...etc.). }\end{array}$ & 3.56 & 1.243 & 1 & High \\
\hline 5 & $\begin{array}{l}\text { The faculty member's ability to formulate the } \\
\text { completion questions with words. }\end{array}$ & 3.43 & 1.336 & 6 & High \\
\hline 6 & $\begin{array}{l}\text { The ability of the faculty member to create file insertion } \\
\text { questions. }\end{array}$ & 3.46 & 1.358 & 4 & High \\
\hline 7 & $\begin{array}{l}\text { The faculty member's ability to create completion } \\
\text { questions with numbers. }\end{array}$ & 3.40 & 1.327 & 7 & High \\
\hline 8 & $\begin{array}{l}\text { The faculty member's ability to create the matching } \\
\text { questions (pictures with words, concepts with terms, } \\
\text { famous people with dates) }\end{array}$ & 3.47 & 1.297 & 3 & High \\
\hline 9 & $\begin{array}{l}\text { The faculty member's ability to design geographic } \\
\text { position (hotspot) questions that the student clicks on } \\
\text { to determine the correct answer }\end{array}$ & 3.37 & 1.235 & 8 & Medium \\
\hline & & 3.45 & 0.657 & & \\
\hline
\end{tabular}


Table (2) shows that the overall mean score for the first dimension, electronic questions, came with a high response degree, with a mean score of (3.45) and a standard deviation of (0.657). This is due to the faculty member's awareness of the importance of formulating questions of all kinds, such as essay questions and ranking questions. This result also indicates the faculty member's ability to design geographic placement questions because of its great role in measuring the cognitive levels of the learner. This result partly agrees with Allam, Gad, and Saleh (2017), which concluded that the feature for controlling the characteristics of questions is available largely on the part of the faculty members.

The second dimension: Multimedia:

The mean scores and standard deviations of the paragraphs of the second dimension were calculated, and then these paragraphs were arranged in descending order according to the mean score of each paragraph, as shown in the following Table:

Table 3. The mean scores and standard deviations of the sample' responses to multimedia

\begin{tabular}{|c|c|c|c|c|c|}
\hline NO. & Paragraph & $\begin{array}{l}\text { Mean } \\
\text { score }\end{array}$ & St. Dev & Order & $\begin{array}{l}\text { Response } \\
\text { rate }\end{array}$ \\
\hline 10 & $\begin{array}{l}\text { The faculty member possesses appropriate text medium } \\
\text { embedding skills. }\end{array}$ & 3.67 & 1.238 & 1 & High \\
\hline 11 & $\begin{array}{l}\text { The faculty member's ability to use the appropriate sound } \\
\text { medium. }\end{array}$ & 3.62 & 1.393 & 2 & High \\
\hline 12 & The ability of the faculty member to employ animation. & 3.54 & 1.495 & 3 & High \\
\hline 13 & The faculty member's ability to add videos into the test. & 3.38 & 1.493 & 5 & Medium \\
\hline 14 & $\begin{array}{l}\text { The faculty member's use of pictures didactically within the } \\
\text { test. }\end{array}$ & 3.42 & 1.466 & 4 & High \\
\hline 15 & $\begin{array}{l}\text { The faculty member's ability to create expressive forms of } \\
\text { the subject's content. }\end{array}$ & 3.25 & 1.511 & 6 & Medium \\
\hline
\end{tabular}

$\begin{array}{llll}\text { Total } & 3.48 & 0.838 & \text { High }\end{array}$

Table (3) shows that the overall score for the second dimension, multimedia, came with a high response degree, with a mean score of (3.48) and a standard deviation of (0.838). This result is due to the faculty member's awareness of the importance of dealing with multimedia and its employment in the educational process and relying on it in building various electronic exams. The faculty member should have sufficient background on using these media in raising the levels of e-learning and enriching the educational experience of the learner.

The third dimension: test time skills

The mean scores and standard deviations of the paragraphs of the third dimension were calculated, and then these paragraphs were arranged in descending order according to the mean score of each paragraph, as shown in the following Table:

Table 4. The mean scores and standard deviations of the sample' responses to test time skills

\begin{tabular}{|c|c|c|c|c|c|}
\hline NO. & Paragraph & $\begin{array}{l}\text { Mean } \\
\text { score }\end{array}$ & St. Dev & Order & Response rate \\
\hline 16 & $\begin{array}{l}\text { The faculty member's ability to specify the time spent on } \\
\text { solving each of the test questions. }\end{array}$ & 3.28 & 1.520 & 4 & Medium \\
\hline 17 & $\begin{array}{l}\text { The faculty member's ability to determine the time spent on } \\
\text { the feedback used for the test. }\end{array}$ & 3.59 & 1.442 & 5 & High \\
\hline 18 & $\begin{array}{l}\text { The faculty member's ability to determine the time consumed } \\
\text { in loading the test pages }\end{array}$ & 3.77 & 1.289 & 1 & High \\
\hline 19 & $\begin{array}{l}\text { The faculty member's ability in determining the appropriate } \\
\text { time for each question according to the type of questions } \\
\text { (closed or open, essay or substantive). }\end{array}$ & 3.45 & 1.416 & 3 & High \\
\hline
\end{tabular}

Table (4) reveals that the overall score for the third dimension, the test time skills, came with a high response degree, with a mean score of (3.53) and a standard deviation of (0.921). This result is explained by the faculty member's awareness of the importance of estimating sufficient time to finish the test. It is also because of the 
member's ability to create questions that are appropriate to the time of the test, whether they are closed, open questions, or essay questions, as they play a major role in determining the time needed for the test.

The fourth dimension: Test evaluation skills

The mean scores and standard deviations of the paragraphs of the fourth dimension were calculated, and then these paragraphs were arranged in descending order according to the mean score of each paragraph, as shown in the following Table:

Table 5. The mean scores and standard deviations of the sample' responses on test evaluation skills

\begin{tabular}{|c|c|c|c|c|c|}
\hline NO. & Paragraph & $\begin{array}{l}\text { Mean } \\
\text { score }\end{array}$ & St. Dev & Order & $\begin{array}{l}\text { Response } \\
\text { rate }\end{array}$ \\
\hline 20 & $\begin{array}{l}\text { The prompt correction for answers, such as answers } \\
\text { related to substantive questions. }\end{array}$ & 3.28 & 1.527 & 5 & Medium \\
\hline 21 & $\begin{array}{l}\text { The faculty member's choice of the necessary } \\
\text { strategies to correct essay questions such as e-mail. }\end{array}$ & 3.33 & 1.442 & 4 & Medium \\
\hline 22 & Annotating the correct answer. & 3.37 & 1.451 & 3 & Medium \\
\hline 23 & Providing suggestions for further studying. & 3.53 & 1.431 & 1 & High \\
\hline 24 & Inspiring learners for correct responses. & 3.48 & 1.454 & 2 & High \\
\hline
\end{tabular}

Table (5) shows that the overall score for the fourth dimension, the test evaluation skill, came with a high response degree, with a mean score of (3.40) and a standard deviation of (1.143). This result is explained by the importance of the faculty member's familiarity with all strategies that facilitate the process of electronically evaluating students' answers according to the quality of each question and providing appropriate feedback. The fifth dimension: Test security skills

The mean scores and standard deviations of the paragraphs of the fifth dimension were calculated, and then these paragraphs were arranged in descending order according to the mean score of each paragraph, as shown in the following table:

Table 6. The mean scores and standard deviations of the sample' responses on test security skills

\begin{tabular}{|c|c|c|c|c|c|}
\hline NO. & Paragraph & $\begin{array}{l}\text { Mean } \\
\text { score }\end{array}$ & St. Dev & Order & $\begin{array}{l}\text { Response } \\
\text { rate }\end{array}$ \\
\hline 25 & Faculty member's protection of students' data. & 3.56 & 1.345 & 1 & High \\
\hline 26 & $\begin{array}{l}\text { The faculty member's prevention of cheating during the } \\
\text { exam. }\end{array}$ & 3.50 & 1.388 & 2 & High \\
\hline 27 & $\begin{array}{l}\text { The faculty member's protection of the testing program from } \\
\text { hacking. }\end{array}$ & 3.34 & 1.450 & 5 & Medium \\
\hline 28 & $\begin{array}{l}\text { The faculty member's protection of the test results from } \\
\text { hacking. }\end{array}$ & 3.37 & 1.433 & 3 & Medium \\
\hline 29 & $\begin{array}{l}\text { Providing students with privacy measures such as username } \\
\text { and password. }\end{array}$ & 3.35 & 1.454 & 4 & Medium \\
\hline \multirow[t]{2}{*}{30} & $\begin{array}{l}\text { Providing a security system that protects test-related paper } \\
\text { data. }\end{array}$ & 3.33 & 1.432 & 6 & Medium \\
\hline & Total & 3.41 & 0.961 & & High \\
\hline
\end{tabular}

Table (6) reveals that the overall score of the fifth dimension, the test security skill, came with a high response degree, with a mean score of (3.41) and a standard deviation of (0.961). This can be attributed to the faculty member's awareness of the importance of providing the necessary protection for students' privacy by using 
the username feature and having a password for each student, as well as providing a security system that can protect the paper information associated with the test.

This result agrees partially with Oluwaseun et al (2016), which indicated that there is potential to enhance the application of web-based testing with integrated biometric systems including fingerprint and face to improve the efficacy and safety of the web-based testing application. The result is partly consistent with Khadka et al (2020), which showed the satisfaction of faculty and students with modern electronic systems in developing and receiving electronic questions from students, in line with recent developments and trends in e-learning.

\section{Results of the Second Question}

To answer the second question of the study, the mean scores and standard deviations of the second part of the scale were calculated, and then these paragraphs were arranged in descending order according to the means scores as shown in the following table:

Table 7. The mean scores and standard deviations of the sample's responses on the skills needed to employ electronic exams

NO. Paragraph $\quad \begin{aligned} & \text { Mean } \\ & \text { score St. Dev Order } \begin{array}{l}\text { Response } \\ \text { rate }\end{array}\end{aligned}$

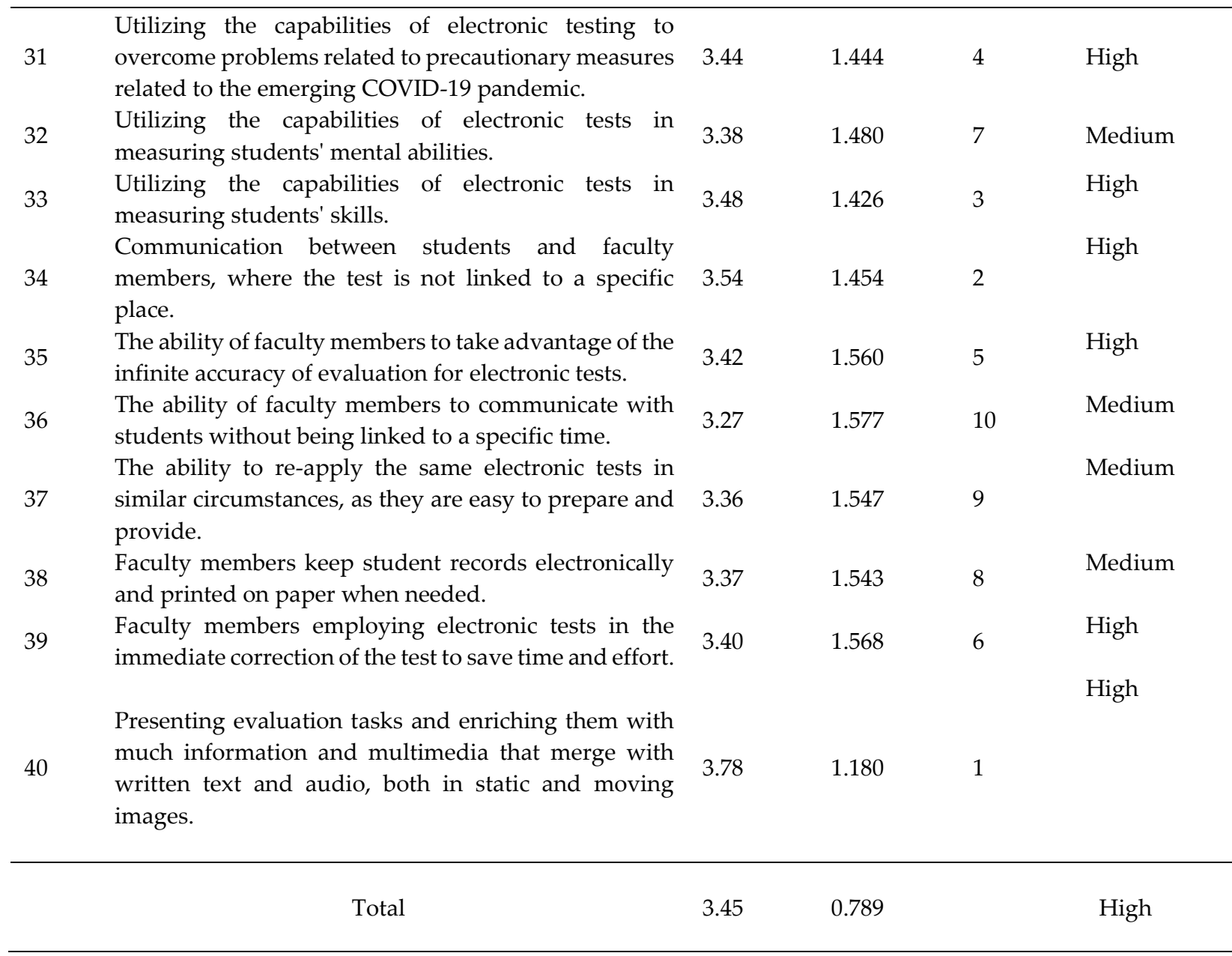

Table (7) reveals that the overall score for the second part of the scale, the skills needed to employ electronic exams, came with a (high) response degree, with a mean score of (3.45) and a standard deviation of (0.789). This result can be attributed to the faculty member's awareness of the importance of employing electronic exams in many different tasks, according to the various features provided by electronic tests, as well as the faculty member's reliance on them to accurately evaluate electronic tests, especially in light of the spread of the Coronavirus pandemic.

This result agrees with Kuikka et al (2014), which indicated the importance of drawing up a list of the skills that teachers need in developing electronic tests. The result also is partly consistent with Hamatsu et al 
(2016), which indicated the existence of positive perceptions among faculty members about the importance of electronic testing at the university. The result also agrees with Osang (2012), which concluded that the electronic test is the best option concerning taking exams in open and distance learning institutions because it helps in solving problems related to paper tests, including human errors in correcting the tests and calculating the results.

\section{CONCLUSION and RECOMMENDATIONS}

This study found that the skills needed to build electronic exams for faculty members at the University of Jeddah in light of the global trend to employ e-learning came with a high response degree, with a mean score of (3.45) and a standard deviation of (0.444). The results also found that the skills needed to employ electronic exams at the University of Jeddah in light of the global trend to employ e-learning came with a high response degree, with a mean score of (3.45) and a standard deviation of (0.789). The results showed the availability of good-level skills for building electronic exams and employing them among faculty members, due to their recent reliance and their students on e-learning because of the recent trends in the use of e-learning at various levels. The study recommends the following:

1. Conducting training courses for faculty members at the University of Jeddah on building electronic exams.

2. Attracting a group of experts to train faculty members at the University of Jeddah to employ electronic exams.

3. Holding scientific seminars on the importance of electronic examination in facilitating the evaluation process for students.

4. Designing a guide for faculty members on employing electronic exams in the educational process.

\section{REFERENCES}

Abubakar, A. S., \& Adebayo, F. O. (2014). Using computer based test method for the conduct of examination in Nigeria: Prospects, challenges and strategies. Mediterranean Journal of Social Sciences, 5(2), 47-55.

Al Jadie, M. Q. (2017). Attitudes of faculty members towards conducting electronic tests and the obstacles to their application at the University of Tabuk. The International Journal of Specialized Education, 6(2), 7877 .

Al-Atrabi, S. (2019). Learning by visualization: e-learning strategy and learning tools. Cairo: Dar Al-Arabi for Publishing and Distribution.

Al-Dmour, R. F. H. (2020). Financial and administrative obstacles to the use of female teachers in the primary and secondary education stage in Karak Governorate for e-learning from their point of view. Journal of Educational and Psychological Sciences, 4(3), 55-40.

Al-Dowayan, M. S. A. (2019). The effect of the difference in the pattern of electronic training (simultaneous asynchronous) on the development of some electronic test design skills among secondary school teachers. Reading and Knowledge Journal, 209, 215-151.

Allam, A. J., Gad, A. D. and Saleh, M. A. M. (2017). The skills needed to build electronic exams in light of the quality standards of the faculty members and their assistants. Education Technology - Studies and Research, (33), 364-327.

Al-Zein, H. A. (2017). The effectiveness of a training program to develop the skills of designing and producing electronic assessment tools for faculty members and the extent of their satisfaction. The Islamic University Journal of Educational and Psychological Studies, 25(3), 45-21.

Amria, A., Ewais, A., \& Hodrob, R. (2018). A framework for automatic exam generation based on intended learning outcomes. CSEDU, 1, 474-480.

Ataman,E. (2020). The investigation of english teachers' views on computer assisted language learning. The Universal Academic Research Journal,2(1)46-57.

Bahbouh, N. M., Binsadiq, M. S., Abi Sen, A. A., Alhafith, A. M., \& Alkhodre, A. B. (2019). Testing system for the blinds in the e-learning environments. International Women Online Journal of Distance Education, 8(2), $1-1$.

Crisp, G. (2011). Teacher's Handbook on e-Assessment, Transforming Assessment-An ALTC Fellowship Activity 18, [online] Available at: http://www.transformingassessment.com/moodle/file.php/84/Handbo ok for teachers.pdf 
Gulbahar, Y., \& Kalelioglu, F. (2015). Competencies for e-instructors: How to qualify and guarantee sustainability. Contemporary Educational Technology, 6(2), 140-154.

Hassan, N. E. M. (2015). The effectiveness of flipped learning based on visual notation in developing the skills of designing electronic tests among faculty members at Umm Al-Qura University. Arab Studies in Education and Psychology, (61), 176-113.

Jeddah University. (2020). Report of the E-Learning Center on the progress of the e-learning process at the University of Jeddah, for the first semester of the academic year 2020. E-learning and distance education center. Retrieved on 8/25/2020, available at https://we.uj.edu.sa/Default.aspx?Site_ID=55660\&Lng=AR\#themeum-topstories

Karagöz,S. (2021). Evaluation of distance education: The sample of guidance and counseling students. The Universal Academic Research Journal,3(1),18-25.

Kaya, B. Y., Kaya, G., \& Dağdeviren, M. (2014). A sample application of web based examination system for distance and formal education. Procedia-Social and Behavioral Sciences, 141, 1357-1362.

Khadka, B. K., Rokaya, B. B., Roka, J., \& Bhatta, P. D. (2020). Perceptions, issues, and challenges towards online and alternative examinations system: A case of Mid-Western University. International Journal of Innovative Science and Research Technology, 5(11), 105-114.

Küçüker, M. S . (2019). The views of the teachers working in vocational high schools about lifelong learning. The Universal Academic Research Journal,1(1),11-26.

Moawad, G. S. I. (2020). The effectiveness of a flipped learning strategy with an adaptive environment in developing the skills of electronic examination design and achievement motivation among faculty members. Journal of the College of Education, 20(1), 584-475.

Mubariz, M. A. and Fakhry, A. M. (2013). E-learning: its concept, environments, courses, its management, its evaluation and its advanced applications. Riyadh: Dar Al Zahraa.

Muhammad, S. T. H. (2017). The effectiveness of a proposed electronic program in developing the skills of preparing electronic tests for teachers of the basic education stage. Journal of Research in the Fields of Specific Education, (5), 229-209.

Oluwaseun, B. R., Muyiwa, O. L. U. G. B. E. B. I., Olanrewaju, B. A., Omolaran, B. B., \& Iyabo, B. S. (2016). Design and Implementation of Web-based Examination System for the University. Journal of Computer Science and Control Systems, 9(2), 5-9.

Rout, G. \& Patnaik, S. (2011) 'A case study on e-examination in Universities of Odisha', International Journal of Internet Computing (IJIC), 1(2), 12-20.

Saif, A. R. (2016). E-training and its relationship to developing the skills of producing electronic tests and critical thinking among students of educational technology. Journal of Research in the Fields of Specific Education, (4), 163-114.

Suleiman, S. A. and Suleiman, M. A. (2020). The effectiveness of using the educational platform Moodle in developing the skills of designing electronic tests among faculty members at Dhofar University. Journal of Educational and Psychological Research, 17(66), 315-288.

Sultania, B and Gilani, H. (2012). Basic approaches to social research. Cairo: Dar Al-Fajr for Publishing and Distribution. 